\title{
Relationship between Perceived Empowerment by Employees and Organizational Citizenship Behavior (Case study: Public Organizations in Bojnourd ${ }^{1}$ )
}

\author{
Mahmood Noori \\ Master of Administration Management \\ Islamic Azad University, Ali adad Katool Branch, Iran \\ 00989153840347 \\ E-mail: Masoud_co341@yahoo.com \\ Dr. Fereydoon Azma \\ Assistant Professor, Management Department \\ Islamic Azad University, Ali Adad Katool Branch, Iran
}

DOI: $\quad 10.6007 /$ IJARBSS/v3-i8/167 URL: http://dx.doi.org/10.6007/IJARBSS/v3-i8/167

\begin{abstract}
The purpose of the present study is to investigate the relationship between perceived empowerment by employees and revealed organizational citizenship behavior. The statistical population includes employees of five organizations (1) in Bojnourd. The sample group ( $n=123$ ) was selected randomly with proportionate stratified sampling method. The result showed that thee is a positive and significant relationship between perceived empowerment components by the employees and organizational citizenship behavior. It is notable that this study is applied type in terms of the goal using descriptive-surveying method.

Keywords: empowerment of employees, dynamic structure framework, participating in decision making, fluid sharing of data, organizational citizenship behavior

\section{Introduction}

In today competitive world, having advanced computers installed is not competitive advantage for companies but instead their human resource is regarded more crucial. Human resource is considered as the most important factor of growth and development of organizations, companies and communities (Scot and Denis 2008:52). Empowered human resource plays a central role in all aspects and it is undeniable element. On this basis, management science holds that an organization must recruit expertise, creative and motivated human resource if it likes to be pioneer in economy and business. Human resource is considered as basis of the real wealth of an organization (Bakhtiari and Daneshgar 2011:78). Successful businesses in the

1 -North Khorasan head office of customs, North Khorasan head office of endowment and charity, North Khorasan veterinary organization, North Khorasan rural cooperative head office, North Khorasan blood transfusion organization
\end{abstract}


world concern about gathering wise and educated human resource who can change the organizations. This can be achieved at most through empowerment of employees (Abolalayi 2010:38). Many researchers have proposed various definitions for empowerment as follows (Abbasi and Abtahi 2007):

*Empowerment is defined as assignment of official authorities and lawful power to employees.

*Empowerment is process of development; it increases power of employees to solve their problems; it elevates the political and social views of employees. Employees can be able to identify environmental factors to control them. Empowerment is not limited to giving power to employees but they can be able to learn knowledge and skills and have motivation for improvement of their performances. Empowerment is a value added process extending from senior management to the lowest rank of the organization.

*Empowerment is a process in which the condition is prepared for empowerment. Data is analyzed in different aspects and goals are transparent; Decision making has boundary and employees are highly efficient. Employees are promoted and qualified based on their skills, knowledge and ability. In empowerment, leadership style is spiritual leadership and the leaders are encouraged to take risk by support of employees.

* Process of empowerment help employees to improve their self-confidence and to overcome the feelings of disability and helplessness. Empowerment in this sense leads to supply internal motivations. It is also means to encourage people to more participation in decision making process impacting on their activities.

From the other hand, investigators suggest that organizational citizenship behavior (OCB) can be defined as extra attempts more than the assigned task of employees. Organ (1988) gives the definition of OCB:" individual behavior that is discretionary, not directly or explicitly recognized by the formal reward system, and that in the aggregate promotes the effective functioning of the organization ". (sited by Moghimi and Ramazan 2011 p.111).

Organizational citizenship behavior is crucial for survival of the organization. Organ holds that OCB can maximize the organization efficacy. Farh et al (1997) explains the components of organizational citizenship behavior based on the cultural conditions of China as follows: courtesy, altruism, conscientiousness, interpersonal coordination, protection of organizational resources. Organ also outlines OCB dimensions as follows: courtesy, altruism, sportsmanship and civic virtue (cited by the same resource p.113).

Therefore, the main concern in this study is to identify the factors affecting on organizational citizenship behavior. If we can identify these typical factors, we would be able to adopt suitable strategies and procedures and to elevate OCB in the organization. As mentioned before, the impact of empowerment of employees on the organization is comprehensive including the perceived empowerment by employees. Thus, we attempt to give an answer to the question" Is there a relationship between perceived empowerment by employees and organizational citizenship behavior? If yes, what type of relation is it?" The reply to this question can help the decision makers in human resource in the organization to present solutions for encouraging organizational citizenship behavior of employees. It is noted that this case study will be implemented in five public organizations in Bojnourd, North Khorasan. The main reasons for selecting these organizations were familiarity of authors with the organizations and determination of their managers to elevate organizational citizenship behavior. The managers of these organization insisted on investigation to reveal the impact of the behavior on the 
performances and productivities of the organizations. Clearly, the results of this study and other similar ones of organizational citizenship behavior can provide the goals of human resource management effectively and can give solutions to the existing issues the decision makers encounter with.

On this basis, followings are main and minor questions in this study:

Main question: Is there a significant relationship between perceived empowerment by personnel in the public organizations in Bojnourd and their organizational citizenship behavior? Minor questions:

1. Is there a significant relationship between "control of workplace decisions in organization" and "revealing organizational citizenship behavior in the personnel?"

2. Is there a significant relationship between "fluidity of information sharing" and "revealing organizational citizenship behavior in the personnel?"

3. Is there a significant relationship between dynamic structural framework" and "revealing organizational citizenship behavior in the personnel?"

\section{The Research Background Overview}

Chiang and Hsieh (2012) concluded that perceived organizational support and psychological empowerment do not impact positively on organizational citizenship behavior. Perceived organizational support does not impact positively on job performance. Psychological empowerment and organizational citizenship behavior impact positively on job performance. Organizational behavior acts as a medium between perceived organizational support and job performance as well as between psychological empowerment and job performance.

Allahyari et al (2011) concluded that there is a positive and significant relationship between organizational learning and empowerment. Also, feeling united with others and self-efficacy can predict organizational learning (positive regression relationship) and there is no significant relationship between empowerment and organizational learning for female and male employees in Tehran University.

Mokhtarian and Mohammadi (2011) studied psychological aspects of empowerment of employees and concluded that employees perceive independence, work structure and clear goals as important factors affecting on psychological empowerment of personnel. It was also revealed that there is not a significant difference among the employees in terms of their views towards the factors impacting on psychological empowerment of personnel. In addition, there was no evidence in terms of significant correlation between demographic features of employees (gender, marriage status and education) and their views towards factors impacting on empowerment of personnel.

Heejung and chen (2011) studied hotel industry and they hold that increasing perceived empowerment requires to recruit customer-oriented personnel, to train them how to give service, to define reward system for them and at last, the communication of service standards must be facilitated.

Thomas and Feldman (2011) studied organizational commitment and organizational citizenship behavior and showed that job duration acts as non-linear medium between effective organizational commitment and organizational citizenship behavior. Job duration lower than 10 years makes the relationship stronger and positive but the relationship gets weaker strength if the person works higher than 10 years for the organization. 
Mahdion, Gahramani and Rezayisharif (2010) tried to explain organizational citizenship behavior using personality. They found that organizational citizenship behavior and personality traits have got above medium position. Organizational citizenship behavior has a significant and positive relationship with many personality traits (agreeableness, openness and so on) and it has negative relationship only with neuroticism. Agreeableness, openness and consciousness can also predict organizational citizenship behavior (based on regression relationship).

Wang (2010) studied the relationship between employees' perception of justice in the organization and their organizational citizenship behaviors. They concluded that organizational justice is a positive predictor for organizational identity of employees. Organizational identity can elevate positively organizational citizenship behavior of employees and plays a medium role between organizational justice and organizational citizenship behavior.

Nediri and Tanova (2010) studied the relationship between hotel staff's perception of justice in North Cyprus and multiple variants related to job (such as organizational citizenship behavior of personnel, hotel staff intention to leave their jobs and personnel job satisfaction). They concluded that firstly, there is a relationship between job perception and job satisfaction parameters, personnel intention to leave and citizenship behavior of personnel and secondly, distributive justice similar to procedural justice is a strong predictor in above relationship.

Ugboro and Obeng (2000) studied the relationship between senior management leadership, empowerment of personnel, job satisfaction and customer satisfaction in organizations adopting philosophy of comprehensive quality management and tried to give guidance to them in terms of empowerment and job satisfaction within the framework of comprehensive quality planning. They concluded that there is a positive and significant relationship between parameters of senior management leadership, empowerment of personnel, job satisfaction and customer satisfaction. They also found that senior management leadership and commitment can facilitate empowerment of personnel and higher job satisfaction in order to achieve comprehensive quality management and higher satisfaction of customers.

Russell, Wendy and Steven (2003) developed reliable and valid scales to identify and scaling three environmental factors (dynamic structural framework, control of workplace decisions in organization and fluidity of information sharing). These factors are related with perception of empowerment by employees and they impact on it. Finally, after field investigation and analyzing the reliability and validity (using Cronbach's Alpha) they identified 19 validated and reliable items (or indexes) on total for measuring three dimensions of empowerment.

4. Conceptual Model and Hypotheses of Research

Based on the above background, following conceptual model is drawn: 


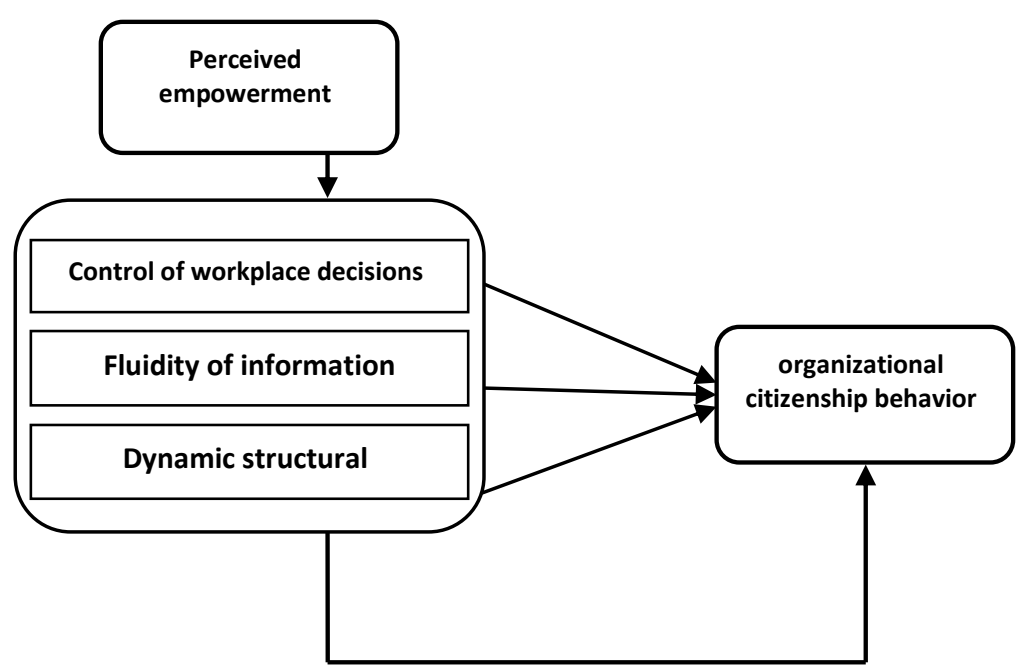

Figure1. Conceptual model

It seems that the best useful frameworks and models are presented by Ugboro and Obeng (2000) as well as by Russell, Wendy and Steven (2003).

The hypotheses are conceptualized based on the above model as follows:

A. Main Hypothesis: Main question: there is a significant relationship between perceived empowerment by personnel in the public organizations in Bojnourd and their organizational citizenship behavior.

Minor hypotheses:

$\mathrm{H} 1$. There is a significant relationship between "control of workplace decisions in organization" and "revealing organizational citizenship behavior in the personnel".

$\mathrm{H} 2$. There is a significant relationship between dynamic structural framework" and "revealing organizational citizenship behavior in the personnel".

H3. There is a significant relationship between "fluidity of information sharing" and "revealing organizational citizenship behavior in the personnel".

\section{Methodology of research}

The present study is descriptive -surveying research and applied method. The statistical population $(n=188)$ includes all personnel of five public organizations in Bojnourd. The sample group $(n=123)$ was selected randomly based on Morgan-Kergsy Table (Danayifard, Alvani and Azar 2009:347) using proportionate stratified sampling method. The tools for gathering data was a closed questionnaire (based on Likert's five-item range) and its reliability and validity were established before the distribution (reliability=91.3\%). Data was analyzed using SPSS software and descriptive-inferential method (Pierson Correlation Test).

\section{Findings}

After inserting data into the software and measuring Pierson Correlation Coefficient, the results are obtained as follows (it is noted that the confidentiality rate is 0.05 ). 


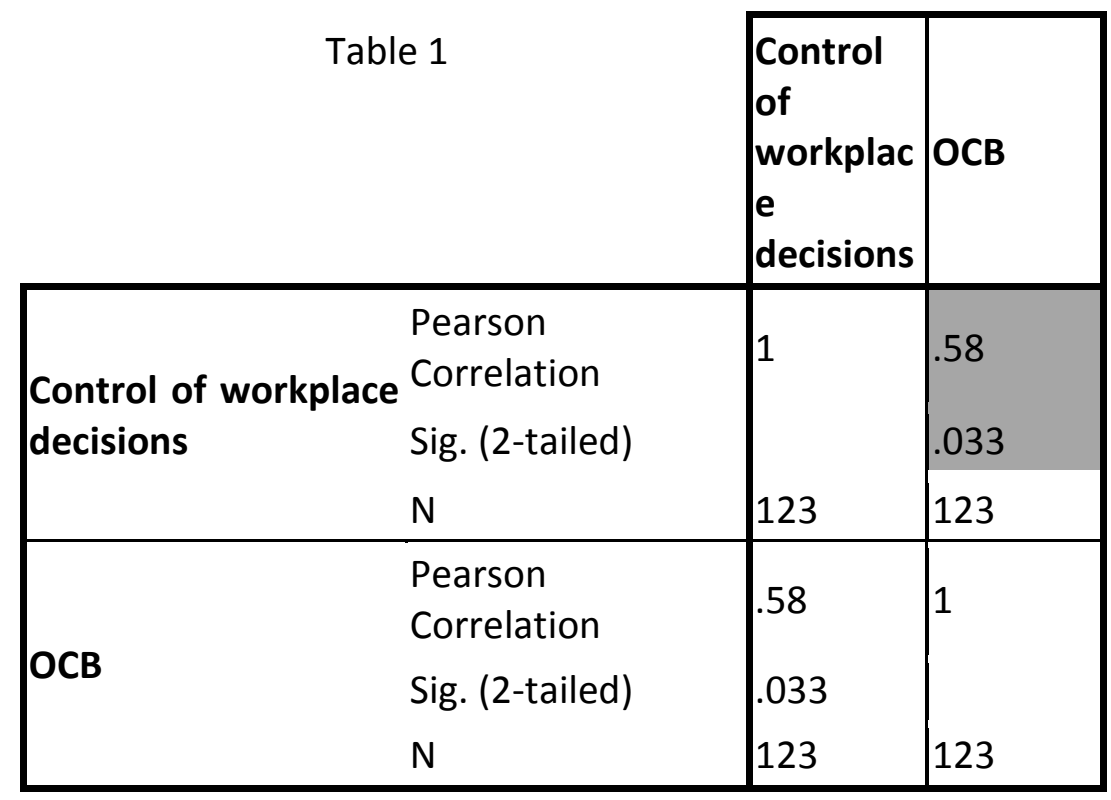

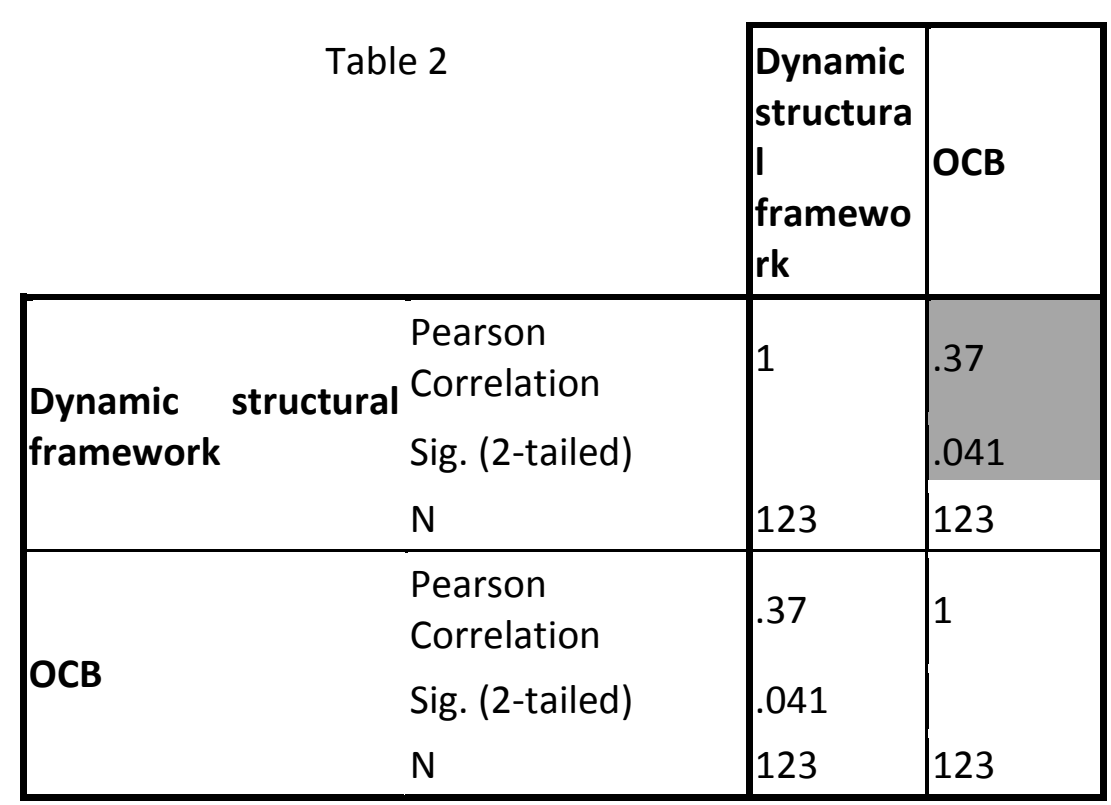




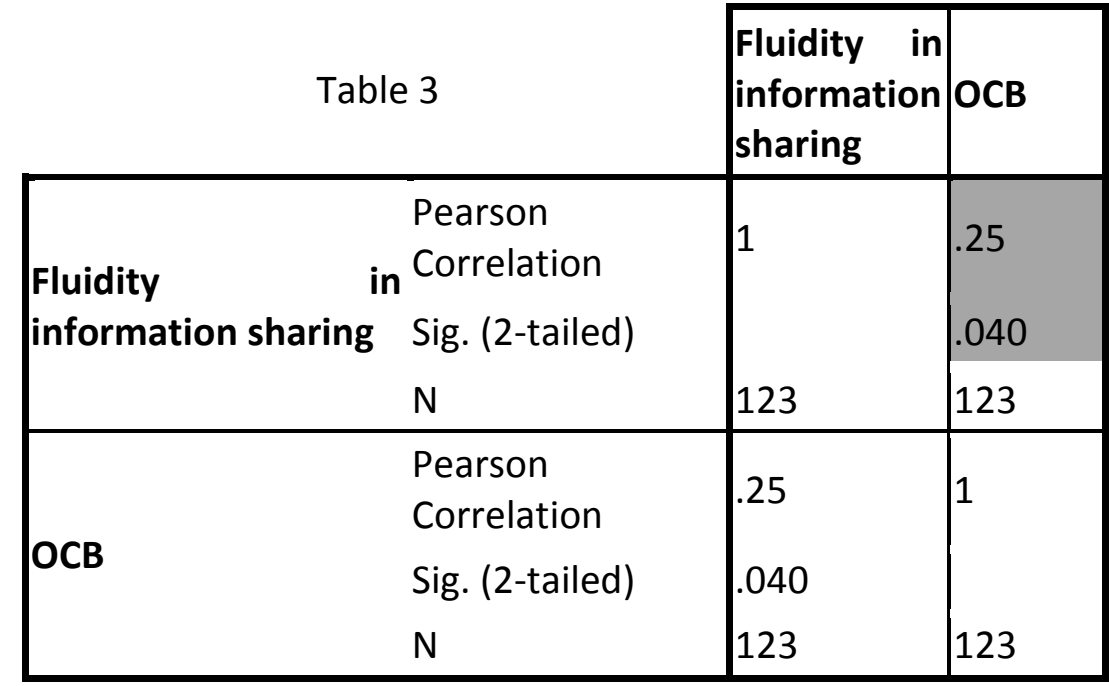

\begin{tabular}{|ll|l|l|}
\cline { 2 - 4 } \multicolumn{1}{c|}{} & $\begin{array}{l}\text { Empowerm } \\
\text { ent }\end{array}$ & OCB \\
\hline \multirow{2}{*}{ Empowerment 4} & $\begin{array}{l}\text { Pearson } \\
\text { Correlation } \\
\end{array}$ & 1 & .42 \\
& Sig. (2-tailed) & & .000 \\
& $\mathrm{~N}$ & 123 & 123 \\
\hline OCB & Pearson & .42 & 1 \\
& Correlation & & \\
& Sig. (2-tailed) & .000 & 123 \\
\hline
\end{tabular}

Since sig. rate in all relation is lower than 0.05, all relationships are significant. According to table1, there is a relatively strong and significant relationship (0.58) between "control of workplace decisions" and "organizational citizenship behavior" so the first hypothesis is established. The table2 shows that there is a positive and significant relationship (0.37) between "dynamic structural framework" and "organizational citizenship behavior" and therefore, the second minor hypothesis is also established. The table 3 shows that there is a positive and significant relationship (0.25) between "fluidity of information sharing" and "organizational citizenship behavior". So, the minor hypothesis 3 is established as well. On the whole, based on the table 4 , there is a positive and significant relationship (0.48) between "perceived empowerment of employees" and "organizational citizenship behavior". Therefore, the main hypothesis of this research is established.

5. Conclusion and Suggestion

As mentioned earlier, all hypotheses of the research are established. The results showed that three components of perceived empowerment by employees (dynamic structural framework, 
control of workplace decisions and fluidity of information sharing) have a positive and significant relationship with organizational citizenship behavior. It means that if the level of perceived empowerment by employees elevates, by rate of $48 \%$ it is possible their organizational citizenship behavior increases as well. This suggests that the managers of studied organizations (and similar ones) must care about empowering their personnel in order that organizational citizenship behavior is encouraged within the organizations because these two variants are interrelated significantly and empowerment variant can be regarded as an effective strategy which would help managers in human resource department. The investigators in this field are advised to develop the model suggested in this study using inferential analysis to probe other aspects of existing relationship between empowerment and organizational citizenship behavior and to give innovative results to science community.

\section{References}

Abtahi, Hossein and Kazemi, Babak (2003):"productivity" Tehran; Commercial Studies and Researches Pub.

Abolalayi, Behzad (2010):"performance management: guiding managers for evaluating and improving employees' performances" Tehran; Industrial Management Organization Pub.

Scott, Sintia and Jeffi, Dennis, Theodore (2011):"empowering employees" translated by Darush Afrouz; Tehran, Institute of Management Research and Training.

Bakhteyari, Hossein and Daneshgar, Mohammad (2011):" general view to empowering employees" Tehran, Behamouz Pub.

Danayiifard, Hasan;Alvani, Seyyedmehdi andAzar, Adel (2009):"methodology of quantitative research in management: comprehensive approach", Tehran, Safar Pub., edit2

Moghimi, Seyyedmohammad, and Ramazan, Majid (2011): " management research:The foundation of organization and management" Vol1 and 2, Tehran, Rahdan Pub

Naderi, Ezaollah and Seynaraghi, Maryam (2011):"research methods and how it is evaluated inhuman science (by emphasizing on psychology), Tehran, Arasbaran Pub.

Allahyari, Rahmatollah., shahbazi, Behzad., Mirkamali, SeyedMohamad., Kharazi, Kamal. (2011). Survey of relationship between the psychological empowerment of employees with organizational learning. Procedia - Social and Behavioral Sciences, Vol. 30, pp.1549-1554.

Chiang, Chun-Fang., Hsieh, Tsung-Sheng. (2012). The impacts of perceived organizational support and psychological empowerment on job performance: The mediating effects of organizational citizenship behavior. International Journal of Hospitality Management, No. 31, pp. 180-190.

Heejung, Ro., Chen, Po-Ju. (2011). Empowerment in hospitality organizations: Customer orientation and organizational support. International Journal of Hospitality Management, No. 30, pp. 422-428.

Mahdiuon, Rouholla.,Ghahramani, Mohammad., Rezaii Sharif, Ali. (2010). Explanation of organizational citizenship behavior with personality.Procedia Social and Behavioral Sciences, No. 5, pp. 178-184.

Mokhtarian, Faranak., Mohammadi, Reza. (2011). Effective factors on psychological aspects of employee empowerment. Case Study: employee's point of views in one of the sub-organizations of Iranian Ministry of Science, Research and Technology. Procedia - Social and Behavioral Sciences, No. 30, PP. $786-790$. 
Nadiri, Halil.,Tanova,Cem. (2010). An investigation of the role of justice in turnover intentions, job satisfaction, and organizational citizenship behavior in hospitality industry. International Journal of Hospitality Management, No. 29,pp. 33-41.

Russell, A. Matthews., Wendy, Michelle Diaz., Steven, G. Cole. (2003). The organizational empowerment scale. Personnel Review, Vol. 32 No. 3, pp. 297-318.

Thomas, W.H. Ng., Feldman, Daniel C. (2011). Affective organizational commitment and citizenship behavior: Linear and non-linear moderating effects of organizational tenure. Journal of Vocational Behavior, No. 79, pp. 528-537.

Ugbaro, Isaiah., Obeng, Kofi. (2000). Top management leadership, employee empowerment, job satisfaction, and customer satisfaction in TQM organizations: an empirical study. Journal of Quality Management, No. 5, p. 247-272.

Wang, Guangling. (2010). The Study on Relationship between Employees' Sense of Organizational Justice and Organizational Citizenship Behavior in Private Enterprises. Energy Procedia, No. 5,pp. 2030-2034. 